\title{
Inhibition of the Endothelial Isoform of Nitric Oxide Synthase Impairs Long-Term Memory Formation in the Chick
}

\author{
Nikki S. Rickard, ${ }^{1}$ Marie E. Gibbs, and Kim T. Ng, \\ Department of Psychology \\ Monash University \\ Clayton, Victoria \\ 3168 Australia
}

\begin{abstract}
Previous studies with general inhibitors of nitric oxide synthase have yielded variable and contradictory results with respect to their effects on memory. This may have been due to differential effects of blocking the various isoforms of this enzyme. We show that day-old chicks trained on a single-trial passive-avoidance task suffered significant memory loss from $\sim 40$ min post-training following post-training intracranial administration of a potent inhibitor of eNOS. Administration of a specific nNOS or iNOS inhibitor at the same time had no effect on retention, although a role for either of these isoforms when administered at a different time after learning has yet to be fully investigated. The onset of memory loss following eNOS inhibition is the same as observed following general NOS inhibition, which suggests that amnestic effects observed in previous studies using nonspecific inhibitors may be attributable to blocking the function of eNOS. The findings indicate that eNOS may play a role in memory formation for this task, which is at least distinct from any role that may be played by nNOS.
\end{abstract}

\section{Introduction}

Nitric oxide (NO) is a putative neurotransmitter in the central nervous system, and is formed on demand through the conversion of L-arginine to L-citrulline by the enzyme nitric oxide synthase

\footnotetext{
${ }^{1}$ Corresponding author.
}

(NOS). There are three isoforms of NOS: the brain or neuronal form (nNOS), the endothelial form (eNOS), and the inducible form (iNOS). The last is formed under pathological conditions and is calcium-independent. In contrast, nNOS and eNOS are constitutive, with activation dependent upon a calcium-calmodulin complex which binds to NOS following an increase in intracellular calcium concentration (for reviews, see Yun et al. 1996; Stuehr 1997). Consequently, synaptic activity resulting in increased intracellular calcium concentration, such as occurs following $N$-methyl-D-aspartate (NMDA) glutamate receptor activation during long-term potentiation (LTP), stimulates NO production. This suggests a possible role for NO in the mechanisms of plasticity associated with learning and memory.

There is extensive evidence showing that inhibition of NO with non-specific NOS inhibitors may impair learning and/or memory formation (for review, see Hawkins 1996), although there have been studies that have failed to find any effect on memory (Tobin et al. 1995; Knepper and Kurylo 1998). In the majority of studies where memory loss has been observed, however, only pretraining injections were found to have deleterious consequences (Böhme et al. 1993; Hölscher and Rose 1993). Pretraining injections of any pharmacological agent may interfere with a range of functions required to learn the task (e.g., sensorimotor functions), without directly disrupting any mechanism specifically involved in the learning process per se, or may interfere with acquisition of the task rather than with memory formation. In contrast, we have shown that inhibition of NO synthesis by $\mathrm{L}-N^{\mathrm{G}}$-nitroarginine methyl ester (L-NAME) or $\mathrm{L}-N^{\mathrm{G}}$-nitroarginine (NArg) impairs retention for a single trial passive avoidance task in neonate chicks from 40 min after training. The presence of normal memory for up to $40 \mathrm{~min}$ post-training indicates that acqui-

LEARNING \& MEMORY 6:458-466 @ 1999 by Cold Spring Harbor Laboratory Press ISSN1072-0502/99 \$5.00

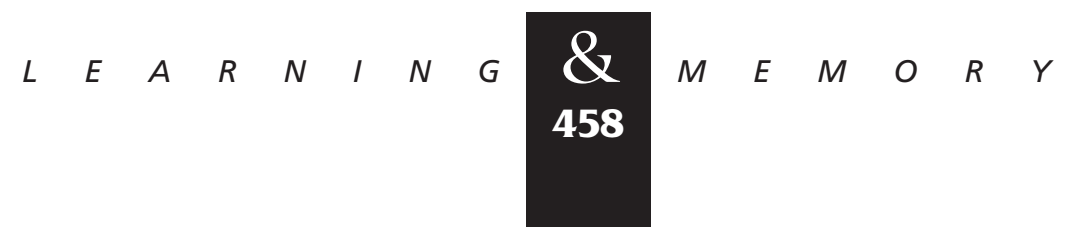


sition of the task was not affected. Moreover, memory loss occurred with inhibitors administered either prior to training or at any time up to 25 min post-training (Rickard et al. 1998). Müller (1996) also provides evidence suggesting that nitric oxide may be involved in just one component of memory storage in the honeybee: long-term retention following a multitrial learning task, with shorter-term retention remaining intact.

It is possible that the inconsistencies observed in the effects of NO inhibition on memory may be attributable, at least partly, to poor differentiation between the different NOS isoforms. General NO inhibitors such as NArg, L-NAME, and $N^{G}$-monomethyl-L-arginine (L-NMMA) have typically been used. These agents have little selectivity for any of the isoforms. Recently, however, a number of potent and relatively selective inhibitors of each NOS isoform have become available.

In the small number of studies that have been conducted with selective inhibitors, systemic administration of 7-nitroindazole (7-NI), which is thought to be specific for nNOS in vivo, has been found to impair spatial learning (Hölscher et al. 1995; Meyer et al. 1998) and object recognition (Prickaerts et al. 1997) in rats, as well as passive avoidance learning in chicks (Hölscher 1994). However, because high doses of 7-NI have been found to increase mean arterial blood pressure in vivo, its selectivity for nNOS has been questioned (Prickaerts et al. 1997). The literature has typically presented inhibition of eNOS as an undesirable side effect of NOS inhibition, particularly when inhibitory drugs are administered peripherally since hypertension could interfere with learning. However, given the increasingly important role ascribed to eNOS in synaptic plasticity, an investigation of the effects of eNOS inhibition on memory processes seems appropriate. Furthermore, the impact of non-specific effects should be reduced considerably by administering inhibitors directly into the brain, and by use of a discrimination index of retention. Although it should be noted that the expression of eNOS has not been demonstrated empirically in the chick brain, the passive avoidance learning paradigm presents an ideal model in which the differential effects of specific NOS inhibitors can be investigated, due to its well-defined temporal parameters. In this paper we present evidence suggesting that eNOS plays an essential role in memory formation for passive avoidance learning, which is at least distinct from any role that nNOS might have played.

\section{Materials and Methods}

A single-trial passive avoidance task was used to train 1- to 2-day-old black Australorp white Leghorn cross cockerels (Research Poultry Farm, Victoria, Australia). Chicks were housed in pairs to reduce isolation stress, and were first pretrained to peck freely at small chrome beads, and then at red and blue glass beads ( $4 \mathrm{~mm}$ diam.). All beads were coated with water and presented in succession for up to $30 \mathrm{sec}$ each. The training trial consisted of a single 10-sec trial during which chicks were presented a red-colored glass bead coated with the chemical aversant methylanthranilate (MeA). Chicks pecking the training bead show typical disgust reactions, such as shaking the head and wiping the beak on the floor. Retention tests were performed at various training-test intervals, and consisted of a 10-sec presentation of a dry red bead, followed by a dry blue bead. The number of pecks at each bead and latency to the first peck were recorded using a hand-held recorder. A different group of 20 chicks was used initially for each data point. However, chicks that failed to peck the aversive bead during the training trial or to peck the blue bead on the retention trial were excluded from subsequent data analyses. Typically, no more than $20 \%$ of chicks in any one group were excluded for these reasons, resulting in 15-20 different chicks for each data point being included in final statistical analyses. Retention levels were indexed by a discrimination ratio defined as the number of pecks at the blue bead to the total number of pecks at both beads on the retention trial. This index provides a continuous measurement of retention, and enables avoidance due to discrimination memory (where the red bead would be avoided, but chicks would continue to peck the blue bead) to be distinguished from avoidance due to non-specific performance effects (where avoidance of both beads would be expected).

Drugs were made up on the morning of the experiment and brought to room temperature. The eNOS inhibitor, diphenyleneiodonium chloride (DPI), the nNOS inhibitors 3-bromo-7-nitroindazole (BNI), and $N$-propyl-L-arginine (NPLA) were dissolved in dimethylsulfoxide (DMSO; <10\%), and then made up to volume in physiological (154 mM) saline, whereas $S$-methyl-t-thiocitrulline (SMTC) and $N$-3-aminomethyl-benzyl-acetamidine (1400W) were dissolved and prepared with saline. (The source of inhibitors was Cayman Chemical, Ann Arbor, MI except for $1400 \mathrm{~W}$, which was obtained

$$
\begin{array}{llllllllllllllll} 
& E & A & R & N & I & N & G & \boldsymbol{Q} \\
459 & M & E & M & O & R & Y
\end{array}
$$


from AG Scientific, San Diego, CA.) Drugs were administered in 10- $\mu$ l volumes to the center of each forebrain by freehand injections with a Hamilton repeating dispenser syringe fitted to a Hamilton repeating dispenser. A stop on the needle (25 gauge) regulated injection depth to $\sim 3.5 \mathrm{~mm}$, the target site being the neostriatal-hyperstriatal complex. At least two regions in this complex have been implicated in passive avoidance learning (Rose and Csillag 1985; Sedman et al. 1992). The accuracy of these injections was monitored by regular histological checks, which showed the target site was reached $85 \%$ of the time.

\section{Results}

\section{PRETRAINING ADMINISTRATION} OF NNOS INHIBITORS

To our knowledge the only drug to have been used to investigate the effects of nNOS inhibition on memory is 7-NI. While 7-NI inhibits eNOS almost as potently as nNOS in vitro, it has been claimed that in whole animals 7-NI does not produce any pressor effect and is therefore selective for nNOS in vivo. However, Prickaerts et al. (1997) found that at a dose of $30 \mathrm{mg} / \mathrm{kg}$, 7-NI did inhibit eNOS as well as nNOS in vivo, and therefore "cannot be regarded as a selective inhibitor of neuronal NO synthase." Furthermore, 7-NI has also been reported to affect dopamine metabolism via monoamine oxidase inhibition (Desvignes et al. 1999). BNI was selected for use in the current study because of its structural similarity to 7-NI, and because it has been reported to be approximately four times more potent than 7-NI in inhibiting nNOS. In addition, it inhibits $\sim 9 \%$ more nNOS activity than does 7-NI (Bland-Ward and Moore 1995).

A dose response study was performed to determine whether administration of BNI impaired retention, and if so, to determine the most effective dose. Concentrations ranging from $10 \mathrm{~nm}$ and $1 \mathrm{~mm}$ (20 $\mu$ l volume per chick) were selected based on effective concentrations determined in previous studies (Furfine et al. 1994; Bland-Ward and Moore 1995). In addition, dose response studies were conducted using SMTC, (concentration range, $1 \mathrm{~nm}$ to $10 \mu \mathrm{M}$ ), and NPLA, (concentration range, $10 \mathrm{~nm}$ to $10 \mu \mathrm{M}$ ), in an attempt to provide convergent evidence for the role of nNOS in memory. SMTC is a potent inhibitor of nNOS in vivo, showing at least 10-fold selectivity for nNOS over eNOS, and at least 18-fold selectivity for $\mathrm{nNOS}$ over iNOS (Furfine et al. 1994; Narayanan et al. 1995). $N^{\omega}$-propyl-L-arginine has been reported to show >3000-fold selectivity for $\mathrm{nNOS}$ over iNOS, and 149-fold selectivity over eNOS (Zhang et al. 1997), which probably makes it the most selective inhibitor of nNOS currently available.

In an attempt to replicate the amnestic effect observed by Hölscher (1994) with intracranial injections, chicks were administered one of the three nNOS inhibitors or the vehicle intracranially $1 \mathrm{hr}$ prior to training. Retention was tested $2 \mathrm{hr}$ posttraining, a time at which protein synthesis-dependent memory is believed to be well established $(\mathrm{Ng}$ and Gibbs 1991). Retention levels were not affected significantly by inhibition of nNOS with any of the three agents tested (range of mean DRs for BNI were 0.844 to 0.944 , and controls were 0.875 ; for SMTC were 0.833 to 0.872 , and controls were 0.886 ; for NPLA were 0.819 to 0.978 , and controls were 0.928). Wide concentration ranges were tested, although the possibility of an inhibitory effect at higher doses than those used here cannot be discounted, as cannot an effect of inhibitors administered at a time later than one hour pre-training. In addition, an effect on long-term memory formation beyond $2 \mathrm{hr}$ post-training cannot be excluded, given that a second protein synthesis-dependent long-term memory stage has been identified 4-6 hr after training (Freeman et al. 1995). Nonetheless, to the extent that the three agents selected varied in potency and specificity, the data present convincing evidence that inhibition of nNOS $1 \mathrm{hr}$ prior to training has no significant effect on memory formation for this task, at least until $2 \mathrm{hr}$ post-training.

\section{THE EFFECT OF SPECIFIC ENOS INHIBITION ON MEMORY}

Because memory remained intact following administration of three different specific nNOS inhibitors, it is possible that the memory loss previously reported with general NOS inhibitors such as L-NAME and NArg is due to inhibition of eNOS. The following studies investigated this possibility.

DPI inhibits acetylcholine-induced relaxation of rabbit $\left(\mathrm{IC}_{50}=0.3 \mu \mathrm{M}\right.$; Stuehr et al. 1991) and rat $\left(\mathrm{IC}_{50}=0.18 \mu \mathrm{M}\right.$; Wang et al. 1993) aortic rings, revealing that it is a potent inhibitor of eNOS. DPI also inhibits NOS in cultured mouse macrophages $\left(\mathrm{IC}_{50}=30 \mathrm{~nm}\right)$, indicating it is also a potent inhibitor of iNOS (Stuehr et al. 1991). There have been no reports of DPI inhibiting nNOS-mediated func-

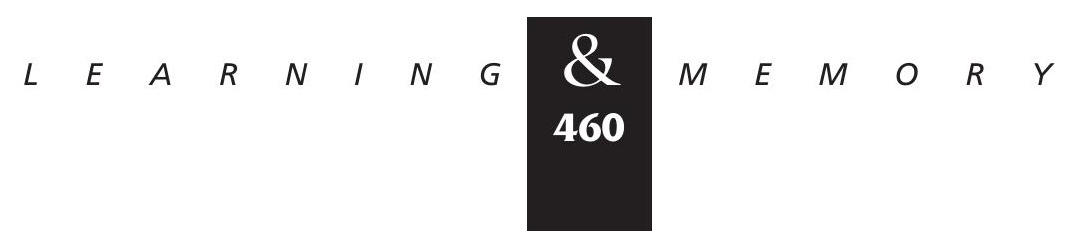


tions, but its affinity for this enzyme is unknown, as the drug's effect on nNOS activity does not appear to have been measured. DPI works by competing with NADPH, which is a cofactor for NO production, and therefore also inhibits other NADPH-utilizing flavoproteins (Yea et al. 1990).

\section{DOSE RESPONSE STUDY}

A dose response study was performed to determine whether administration of DPI impaired retention, and, if so, at which dose. Previous studies have found that concentrations that effectively inhibited eNOS in vitro ranged from 0.3 to $10 \mu \mathrm{M}$ (Rand and Li. 1993; Wang et al. 1993; Dodd-o et al. 1997), although considerably higher doses have been used for rats in vivo (1.6-3.8 mg/kg; Wang and Pang 1993; Wang et al. 1993). Concentrations ranging from $1 \mathrm{~nm}$ and $100 \mu \mathrm{M}(20 \mu \mathrm{l}$ volume per chick) were used based on effective concentrations used in previous in vitro and in vivo studies, and were administered to different groups of 20 chicks. A control group of chicks was administered the vehicle on each experimental day to control for the effects of injection. All injections were given immediately (within $10 \mathrm{sec}$ ) after training, and retention tests were performed $2 \mathrm{hr}$ post-training.

Administration of DPI impaired retention for the passive avoidance task (Fig. 1), with concentrations of $1 \mu \mathrm{M}$ and above resulting in moderate retention loss. A one-way ANOVA confirmed a significant concentration effect $[\mathrm{F}(7,172)=5.322$, $P<0.001$ ], with post hoc Dunnett's tests revealing that only chicks administered either 1, 10, or 100

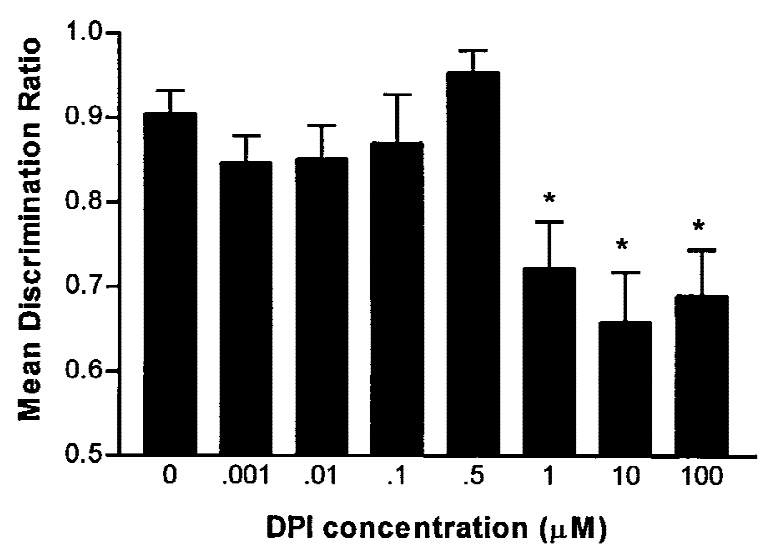

Figure 1: Dose response function for diphenyleneiodonium chloride (DPI) administered immediately after training. Retention was tested $2 \mathrm{hr}$ post-training $\left({ }^{*} P<0.05\right)$.

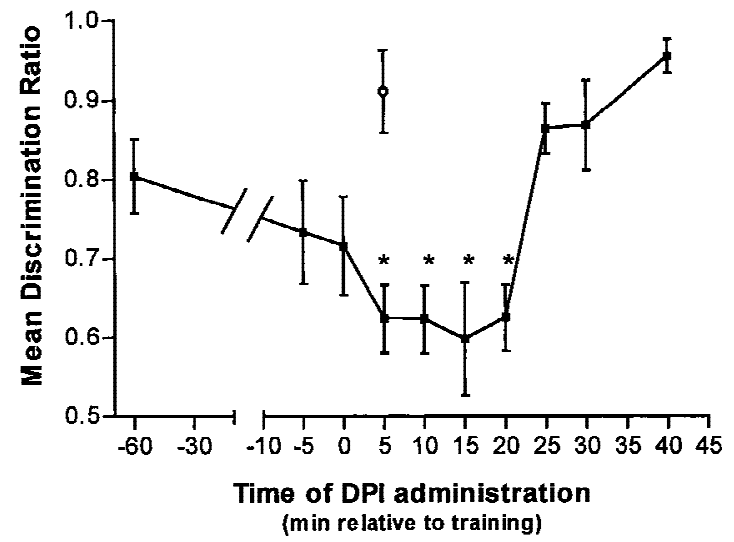

Figure 2: Retention (tested $2 \mathrm{hr}$ post-training) following administration of $1 \mu \mathrm{M}$ DPI $(\boldsymbol{\square})$ at various times relative to training $\left({ }^{*} P<0.05\right) .(\bigcirc)$ Vehicle.

$\mu$ M DPI exhibited significantly lower retention levels $(P<0.05)$ than those of chicks administered the vehicle. This is consistent with previous findings that concentrations around $10 \mu \mathrm{m}$ were most effective in inhibiting NOS activity in vitro (Stuehr et al. 1991; Dodd-o et al. 1997). However, the degree of inhibition caused by DPI in this study was not marked. This may be due to administration of the drug at a time that does not optimally inhibit NOS activity, a possibility that was examined in the following time of administration study.

\section{TIME OF ADMINISTRATION STUDY}

DPI (1 $\mu \mathrm{M})$ was administered (20 $\mu \mathrm{l}$ /volume per chick) to different groups of chicks at $1 \mathrm{hr}$ or 5 min prior to training, immediately after training, or at 5, 10, 15, 20, 25, 30, or $40 \mathrm{~min}$ after training. Control chicks were administered the vehicle 5 min post-training, and all chicks were tested $2 \mathrm{hr}$ post-training.

Retention at 120 min post-training was markedly impaired when $1 \mu \mathrm{M}$ DPI was administered at any time between 5 and 20 min post-training (Figure 2). A one-way ANOVA revealed a significant time of administration main effect $[F(10,225)=6.735, P<0.001]$, and post hoc Dunnett's tests confirmed that retention levels of chicks administered DPI at 5, 10, 15, or $20 \mathrm{~min}$ post-training were significantly lower than those of control chicks. The finding that administration of DPI must occur within 20 min of learning is similar to that observed with the less specific NO inhibitors, NArg, and L-NAME (Rickard et al. 1998). Furthermore, the efficacy of post-training injections

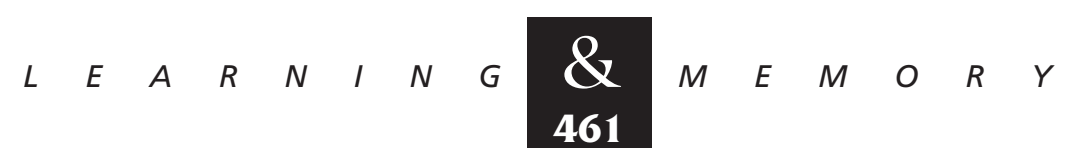




\section{Rickard et al.}

confirms that this effect of eNOS inhibition is on memory processes rather than on acquisition of the task.

\section{RETENTION FUNCTION}

Memory loss for the passive avoidance task previously has been observed to begin from $\sim 40$ min post-training following inhibition of NOS with L-NAME or NArg (Rickard et al. 1998). A retention study was thus performed with DPI to determine if the onset time of amnesia was similar to that observed with nonspecific NOS inhibition. Chicks were administered $1 \mu \mathrm{M}$ DPI 5 min post-training, and retention levels were measured in different groups of chicks at 10, 20, 30, 40, 50, 60, 80, 120, and $180 \mathrm{~min}$ after training. A control group of chicks that was administered the vehicle $5 \mathrm{~min}$ post-training was tested $120 \mathrm{~min}$ after training.

Following administration of DPI, retention was high for $\sim 30 \mathrm{~min}$, after which retention levels dropped considerably (Fig. 3). A one-way ANOVA confirmed a significant time of test effect $[F(9,182)=4.490, P<0.001]$, and post hoc Dunnett's tests showed that DPI-treated chicks tested at 40,60, 120, and $180 \mathrm{~min}$ post-training yielded significantly lower retention levels than those of control chicks. This pattern of retention loss is very similar to that observed following administration of NArg or L-NAME, both of which resulted in significant retention losses $\sim 40 \mathrm{~min}$ post-training.

While DPI is a very potent inhibitor of eNOS, its specificity is limited. DPI is known to inhibit iNOS and other NADPH-utilizing enzymes, and its effect on nNOS is unknown. The following studies were therefore conducted to determine whether

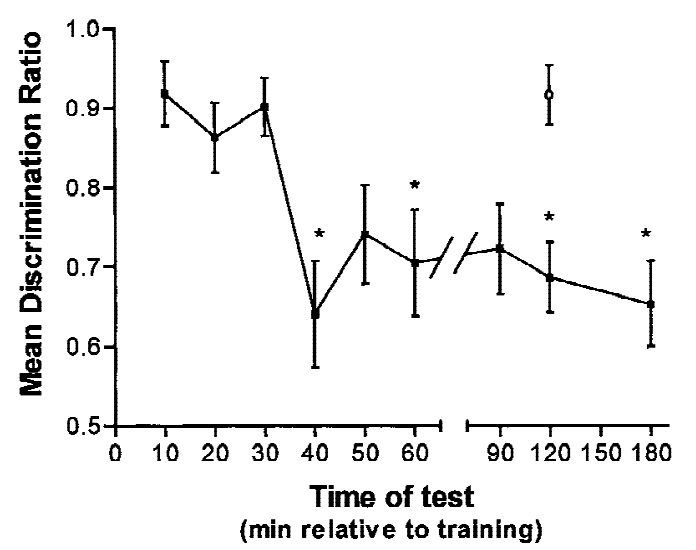

Figure 3: Retention function of chicks administered 1

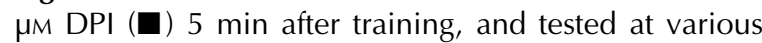
times following training $\left({ }^{*} P<0.05\right)$. ( $)$ Vehicle. the memory loss observed following administration of DPI at $5 \mathrm{~min}$ post-training could be accounted for by inhibition of either iNOS or nNOS.

\section{POST-TRAINING ADMINISTRATION OF INOS AND} NNOS INHIBITORS

In addition to inhibiting eNOS, DPI is also a potent inhibitor of iNOS with slightly greater selectivity for iNOS over eNOS (3.6-fold in rat aorta) (Stuehr et al. 1991). Although it would seem unlikely that the inducible form of NOS is involved in memory processes, it is important to exclude this possibility. A dose response study for the selective iNOS inhibitor $1400 \mathrm{~W}$ was performed. The drug was administered $5 \mathrm{~min}$ post-training, the same time at which DPI was found to produce significant memory loss. Concentrations between $100 \mathrm{~nm}$ and $1 \mathrm{~mm}$ yielded no significant effects on retention for this task when chicks were tested $2 \mathrm{hr}$ after training (range of mean DRs, 0.840 to 0.895 ; control, 0.881).

Because the affinity of DPI for the nNOS enzyme is unknown, it is possible that the memory loss induced by this drug was due to inhibition of nNOS. A dose response study for the most selective and potent nNOS inhibitor (NPLA) available was performed, using one of the administration times ( 5 min post-training) found to be effective for DPI. Chicks administered NPLA concentrations ranging between $10 \mathrm{~nm}$ and $100 \mu \mathrm{m}$, and tested $2 \mathrm{hr}$ after training, were found to demonstrate retention levels that were not significantly different from those of chicks administered the vehicle (range of mean Drs, 0.869 to 0.929; control 0.891).

It can therefore be inferred that the amnestic effect of DPI administered 5 min after passive avoidance training is more likely to be due to inhibition of eNOS, than to inhibition of iNOS or nNOS. Although DPI also inhibits NADPH-utilizing enzymes other than NOS, our previous findings using the non-specific NOS inhibitors L-NAME and NArg, which do not inhibit other NADPH-utilizing enzymes, also revealed onset of memory loss at 40 min post-training. When taken together with the current data, these findings strengthen the conclusion that the DPI-induced memory loss is due to inhibition of eNOS.

\section{Discussion}

The present results suggest eNOS is implicated in the consolidation of memory for a passive avoidance learning task in the chick. This is, to our knowl-

$$
\begin{array}{lllllllllllllll} 
& E & A & R & N & I & N & G & \underset{4}{\mathbf{Q}} \\
\mathbf{Q} & M & E & M & O & R & Y
\end{array}
$$


edge, the first evidence that eNOS plays a central role in memory processing. Moreover, the retention function obtained following eNOS inhibition replicates that obtained with the general $\mathrm{NO}$ inhibitors, NArg, and L-NAME (Rickard et al. 1998). It is possible, therefore, that inhibition of eNOS is responsible for the amnestic effects of these general NOS inhibitors.

In contrast, we failed to obtain evidence that $\mathrm{nNOS}$ is required for this form of learning, when administered at either $1 \mathrm{hr}$ prior to training, or at 5 min post-training. This finding is inconsistent with a number of previous studies, which have found that peripheral administration of the nNOS inhibitor 7-NI prior to training impaired various forms of learning (Hölscher 1994; Hölscher et al. 1995; Prickaerts et al. 1997; Meyer et al. 1998). However, there is some doubt as to the status of this drug as a specific inhibitor of nNOS. Although it is known that 7-NI inhibits both eNOS and nNOS in vitro, it has been claimed that 7 -NI is quite selective for nNOS in vivo since blood pressure does not appear to be affected when 7-NI is administered (Moore et al. 1993). Nonetheless, Prickaerts et al. (1997) found that an intraperitoneal (i.p.) dose of $30 \mathrm{mg} /$ $\mathrm{kg}$ (but not $10 \mathrm{mg} / \mathrm{kg}$ ) significantly increased mean arterial blood pressure, and thus must have inhibited eNOS to some degree. Meyer et al. (1998) reported nonsignificant increases in systolic blood pressure following i.p. administration of $65 \mathrm{mg} / \mathrm{kg}$ 7-NI, although whether the change in mean arterial pressure was significant is not reported. It is likely, then, that when Hölscher et al. (1995) used a 30 $\mathrm{mg} / \mathrm{kg}$ dose (i.p.) to investigate the effects of nNOS inhibition of spatial learning in the rat, eNOS was also inhibited. Similarly, when Hölscher (1994) administered $40 \mathrm{mg} / \mathrm{kg}$ 7-NI i.p. to investigate the effects of nNOS inhibition on passive avoidance learning in the chick, the memory loss may have been due to eNOS rather than nNOS inhibition (although it is notable that eNOS inhibition $1 \mathrm{hr}$ pretraining only resulted in a mild retention loss in our laboratory). Furthermore, previous studies have used peripheral administration of 7-NI, making the possibility of nonspecific effects such as hypertension, more likely. The current observation that memory was intact following intracranial administration of specific nNOS inhibitors would seem to support this conclusion. However, it must be emphasized that only two times of administration were tested for nNOS inhibitors in the current study. A more systematic investigation of administration times, and longer train-test intervals follow- ing $\mathrm{nNOS}$ inhibition is currently in progress in our laboratory to investigate the possibility of a separate role of nNOS in memory formation for this task.

Alternatively, we may have failed to observe an effect of nNOS inhibition on retention because the brain region targeted by our injections may not be the site of learning-induced NO activity. It has been established that nNOS is sparse in the intermediate medial hyperstriatal ventrale (IMHV) of the chick brain (Ambalavanar et al. 1994; Brüning et al. 1994; von Bartheld and Schober 1997), the main area within the hyperstriatal-neostriatal area targeted by our injections. We administered nNOS inhibitors into this region because the IMHV previously has been implicated in both passive avoidance learning and imprinting. However, since Hölscher and colleagues (Hölscher 1994; Hölscher et al. 1995) administered 7-NI intraperitoneally, the entire brain would have been accessed by the drug. For instance, the lobus parolfactorious (LPO) is an area in the chick brain that contains large quantities of nNOS (Brüning 1993; von Barheld and Schober 1997), and has also been implicated in memory processing (Gilbert et al. 1991; Gigg et al. 1994). Unfortunately, it is possible that, with peripheral administration, a range of processes nonspecific to memory would have also been exposed to the drug. It is difficult, therefore, to exclude drug effects on performance in such studies. We are currently investigating the effects of nNOS inhibitor administered intracranially into several other regions of the chick brain, including the LPO.

The mechanism for which eNOS is required for memory cannot be determined from the current results. However, a role of eNOS in learning and memory is consistent with several functions in which eNOS is known to be involved. There is evidence that $\mathrm{NO}$ acts as a retrograde messenger, which, from the postsynaptic cell where LTP is induced, signals the presynaptic cell to increase the release of glutamate (O'Dell et al. 1991). Because of its localization in neuronal tissue in mammalian brain, it has generally been assumed that nNOS is the isoform involved in synaptic plasticity. However, hippocampal LTP is sustained in knockout mice deficient for nNOS (O'Dell et al. 1994; Son et al. 1996; Wilson et al. 1997) or eNOS (Son et al. 1996), but not both (O'Dell et al. 1994; Son et al. 1996), indicating that either enzyme may be sufficient for its role in LTP.

It is possible that eNOS may be even more

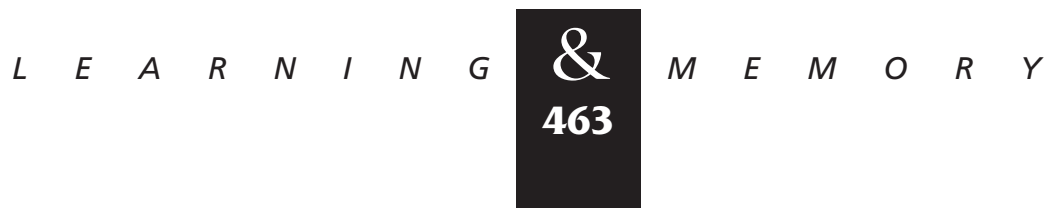




\section{Rickard et al.}

critical for LTP under certain conditions than nNOS. For instance, LTP induced by a weak stimulus significantly reduced in mice mutant for eNOS, but not for nNOS (Wilson et al. 1997, 1999), and neocortical LTP was found to not be sustainable in eNOS-deficient mice (Haul et al. 1999). In addition, disruption of the normal eNOS myristoylation process (anchoring eNOS to the neuronal membrane) inhibits LTP in a hippocampal slice preparation, an effect which is reversed when a membrane-anchoring protein is added to the bath (Kantor et al. 1996). Despite the nomenclature, eNOS has been found in mammalian neural tissue, with greater immunostaining found for eNOS than nNOS in hippocampal CA1 pyramidal cells in both rat (Dinerman et al. 1994; O'Dell et al. 1994) and human (Doyle and Slater 1997). If an LTP-like process underlies memory for passive avoidance learning in the chick, the present evidence suggests that the role of eNOS cannot be substituted by nNOS.

Another interesting possibility is that NO-mediated cerebrovasodilation may play a significant role in memory processing. The fact that peripherally administered eNOS inhibitors can be hypertensive means that eNOS inhibition might artefactually impair performance on a memory task due to factors non-specific to memory processing per se. However, this concern is minimal when the drug is administered directly into the brain. It is of interest, then, that enhanced cerebral vasodilation following neural activity has been found to be mediated by NO (Gally et al. 1990; Adachi et al. 1992; Iadecola 1992, 1993; Faraci and Breese 1993). The consequential increase in blood supply could provide an additional source of essential resources, such as glucose or oxygen, to activated neurons. Retention for the passive avoidance task in the dayold chick after $30 \mathrm{~min}$ or so after training has been shown to depend on energy supply beyond that available from oxidative metabolism in neuronal and astrocytic citric acid cycles, possibly derived from astrocytic glycogenolysis (O'Dowd et al. 1994). Inhibiting blood flow could impair critical energy-dependent processes occurring in neurons at this time. In this context, it is of interest that within our paradigm, weakly reinforced learning typically results in memory retention for $\sim 30 \mathrm{~min}$. However, administration of a number of vasodilatory agents including the NO donor, sodium nitroprusside, and the $\alpha_{1}$-adrenergic blocker prazosin, following weakly reinforced training results in the establishment of long-term memory (Rickard et al. 1994; M.E. Gibbs and R.J. Summers, Pers. comm.).
Although the mechanism by which NO exerts a role in memory remains unclear, the current findings raise the possibility that eNOS may play a significant role in memory formation for at least one form of learning. However, just as NO is not required for all forms of learning, or for LTP under all conditions, it is possible that nNOS may play a greater role than eNOS in other forms of learning. Furthermore, a role for nNOS in passive avoidance learning may exist at a time distinct from eNOS activity, which was not uncovered in the present study. The findings reported here suggest, in the least, that research into the roles of NO in memory processing should include investigation of the role of the endothelial isoform of NOS.

\section{Acknowledgments}

This research was supported in part by a grant from the Australian Research Council. All procedures were performed within the guidelines of the National Health \& Medical Research Council (NHMRC) Australian Code of Practice for the Care and Use of Animals for Scientific Purposes.

The publication costs of this article were defrayed in part by payment of page charges. This article must therefore be hereby marked "advertisement" in accordance with 18 USC section 1734 solely to indicate this fact.

\section{References}

Adachi, T., O. Inanami, and A. Sato. 1992. Nitric oxide (NO) involved in increased cerebral cortical blood flow following stimulation of the nucleus of Meynert in anesthetized rats. Neurosci. Lett. 139: 201-294.

Ambalavanar, R., B.J. McCabe, and G. Horn. 1994. NADPH diaphorase (nitric oxide synthase) in a part of the chick brain involved in imprinting. Brain Res. 644: 160-163.

Bland-Ward, P.A. and P.K. Moore. 1995. 7-Nitro indazole derivatives are potent inhibitors of brain, endothelium and inducible isoforms of nitric oxide synthase. Life Sci. 57: PL131-135.

Böhme, G.A., C. Bon, M. Lemaire, M. Reibaud, O. Piot, J. Stutzmann, A. Doble, and J. Blanchard. 1993. Altered synaptic plasticity and memory formation in nitric oxide synthase inhibitor-treated rats. Proc. Natl. Acad. Sci. 90: 9191-9194.

Brüning, G. 1993. Localization of NADPH-diaphorase in the brain of the chicken. J. Comp. Neurol. 334: 192-208.

Brüning, G., U. Funk, and B. Mayer. 1994.

Immunocytochemical localization of nitric oxide synthase in the brain of the chicken. NeuroReport 5: 2425-2428.

Desvignes, C., L. Bert, L. Vinet, L. Denoroy, B. Renaud, and L. Lambás-Señas. 1999. Evidence that the neuronal nitric oxide synthase inhibitor 7-nitroindazole inhibits monoamine oxidase in the rat: In vivo effects on extracellular striatal

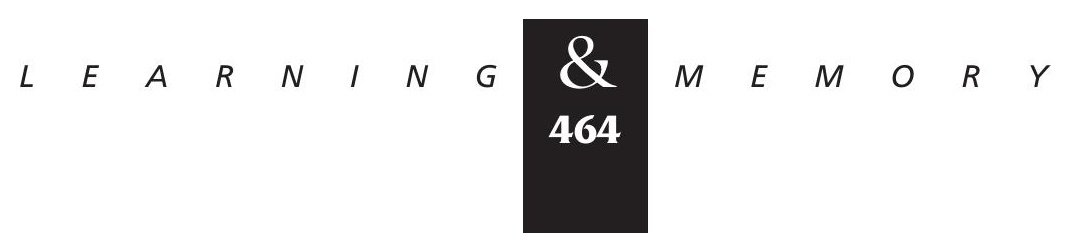


dopamine and 3,4-dihydroxyphenylacetic acid. Neurosci. Lett. 261: 175-178.

Dinerman, J.L, T.M. Dawson, M. J. Schell, A. Snowman, and S. H. Snyder. 1994. Endothelial nitric oxide synthase localized to hippocampal pyramidal cells: Implications for synaptic plasticity. Proc. Natl. Acad. Sci. 91: 4214-4218.

Dodd-o, J.M., G. Zheng, H.S. Silverman, E.G. Lakatta, and R.C. Ziegelstein. 1997. Endothelium-independent relaxation of aortic rings by the nitric oxide synthase inhibitor diphenyleneiodonium. Br. J. Pharmacol. 120: 857-864.

Doyle, C.A. and P. Slater. 1997. Localization of neuronal and endothelial nitric oxide synthase isoforms in human hippocampus. Neuroscience 76: 387-395.

Faraci, F.M. and K.R. Breese. 1993. Nitric oxide mediates vasodilation in response to activation of $\mathrm{N}$-methyl-D-aspartate receptors in brain. Circ. Res. 72: 477-480.

Freeman, F.M., S.P.R. Rose, and A.B. Scholey. 1995. Two windows of anisomycin-induced amnesia for passive avoidance training in the day-old chick. Neurobiol. Learn. Mem. 63: 291-295.

Furfine, E.S., M.F. Harmon, J.E Paith, R.G. Knowles, M. Salter, R.J. Kiff, C. Duffy, R. Hazelwood, J.A. Oplinger, and E.P. Garvey. 1994. Potent and selective inhibition of human nitric oxide synthases. J. Biol. Chem. 269: 26677-26683.

Gally, J.A., P.R. Montague, G.N. Reeke, and G.M. Edelman. 1990. The NO hypothesis: Possible effects of a short-lived, rapidly diffusible signal in the development and function of the nervous system. Proc. Natl. Acad. Sci. 87: 3547-3551.

Gigg, J., T.A. Patterson, and S.P. Rose. 1994. Increases in neuronal bursting recorded from the chick lobus parolfactorius after training are both time-dependent and memory-specific. Eur. J. Neurosci. 6: 31313-31319.

Gilbert, D.B., T.A. Patterson, and S.P. Rose. 1991. Dissociation of brain sites necessary for registration and storage of memory for a one-trial passive avoidance task in the chick. Behav. Neurosci. 105: 553-561.

Haul, S., A. Gödecke, J. Schrader, H.L. Haas, and H.J. Luhmann. 1999. Impairment of neocortical long-term potentiation in mice deficient of endothelial nitric oxide synthase. J. Neurophysiol. 81: 494-497.

Hawkins, R.D. 1996. NO honey, I don't remember. Neuron 16: $465-467$.

Hölscher, C. 1994. 7-Nitro indazole, a neuron-specific nitric oxide synthase inhibitor, produces amnesia in the chick. Learn. \& Mem. 1: 213-216.

Hölscher, C. and S.P.R. Rose. 1993. Inhibiting synthesis of the putative retrograde messenger nitric oxide results in amnesia in a passive avoidance task in the chick. Brain Res. 619: 189-194.
Hölscher, C., L. McGlinchey, R. Anwyl, and M.J. Rowan. 1995. 7-Nitro indazole, a selective neuronal nitric oxide synthase inhibitor in vivo, impairs spatial learning in the rat. Learn. \& Mem. 2: 267-278.

Iadecola, C. 1992. Nitric oxide participates in the cerebrovasodilation elicited from cerebellar fastigial nucleus. Am. J. Physiol. 263: R1156-R1161.

1993. Regulation of the cerebral microcirculation during neural activity: Is nitric oxide the missing link? Trends Neurosci. 16: 206-214.

Kantor, D.B., M. Lanzrein, J. Stary, G.M. Sandoval, W.B. Smith, B.M. Sullivan, N. Davidson, and E.M. Schuman. 1996. A role for endothelial NO synthase in LTP revealed by adenovirus-mediated inhibition and rescue. Science 274: $1744-1748$.

Knepper, B.R. and D.D. Kurylo. 1998. Effects of nitric oxide synthase inhibitor $N^{G}$-nitro-L-methyl ester on spatial and cued learning. Neuroscience 83: 837-841.

Meyer, R.C., E.L. Spangler, N. Patel, E.D. London, and D.K. Ingram. 1998. Impaired learning in rats in a 14-unit T-maze by 7 -nitroindazole, a neuronal nitric oxide synthase inhibitor, is attenuated by the nitric oxide donor, molsidomine. Eur. J. Pharmacol. 341: 17-22.

Moore, P.K., R.C. Babbedge, P. Wallace, Z.A. Gaffen, and S.L. Hart. 1993. 7-Nitro indazole, an inhibitor of nitric oxide synthase, exhibits anti-nociceptive activity in the mouse without increasing blood pressure. Br. J. Pharmacol. 108: 296-297.

Müller, U. 1996. Inhibition of nitric oxide synthase impairs a distinct form of long-term memory in the honeybee, Apis mellifera. Neuron 16: 541-549.

Narayanan, K., L. Spack, K. McMillan, R.G. Kilbourn, M.A. Hayward, B.S. Siler Masters, and O.W. Griffith. 1995. S-Alkyl-L-thiocitrullines. J. Biol. Chem. 270: 11103-11110.

Ng, K.T. and M.E. Gibbs. 1991. Stages in memory formation: A review. In Neural and behavioural plasticity: The use of the domestic chick as a model (ed. R.J. Andrew), pp. 351-369. Oxford University Press, Oxford, UK.

O'Dell, T.J., R.D. Hawkins, E.R. Kandel, and O. Arancio. 1991. Tests of the roles of two diffusible substances in long-term potentiation: Evidence for nitric oxide as a possible early retrograde messenger. Proc. Natl. Acad. Sci. 88: $11285-11289$.

O'Dell, T.J., P.L. Huang, T.M. Dawson, J.L. Dinerman, S,H. Snyder, E.R. Kandel, and M.C. Fishman. 1994. Endothelial NOS and the blockade of LTP by NOS inhibitors in mice lacking neuronal NOS. Science 265: 542-546.

O'Dowd, B.S., M.E. Gibbs, K.T. Ng, E. Hertz, and L. Hertz. 1994. Astrocytic glycogenolysis energizes memory processes in neonate chicks. Dev. Brain Res. 78: 137-141. 


\section{Rickard et al.}

Prickaerts, J., H.W.M. Steinbusch, J.F.M. Smits, and J. de Vente. 1997. Possible role of nitric oxide-cyclic GMP pathway in object recognition memory: Effects of 7-nitroindazole and zaprinast. Eur. J. Pharmacol. 337: 125-136.

Rand, M.J. and C.G. Li. 1993. The inhibition of nitric oxide-mediated relaxations in rat aorta and anococcygeus muscle by diphenylene iodonium. Clin. Exp. Pharmacol. Physiol. 20: 141-148.

Rickard, N.S., K.T. Ng, and M.E. Gibbs. 1998. Further support for nitric oxide-dependent memory processing in the day-old chick. Neurobiol. Learn. Mem. 69: 79-86.

Rickard, N.S., K.T. Ng, and M.E. Gibbs. 1994. A nitric oxide agonist stimulates consolidation of long-term memory in the 1-day-old chick. Behav. Neurosci. 108: 640-644.

Rose, S.P.R. and A. Csillag. 1985. Passive avoidance training results in lasting changes in deoxyglucose metabolism in left hemisphere regions of chick brain. Behav. Neural Biol. 44: $315-324$.

Sedman, G., B. O'Dowd, N. Rickard, M.E. Gibbs, and K.T. Ng. 1992. Brain metabolic activity associated with long-term memory consolidation. Mol. Neurobiol. 5: 351-353.

Son, H., R.D. Hawkins, K. Martin, M. Kiebler, P.L. Huang, M.C. Fishman, and E.R. Kandel. 1996. Long-term potentiation is reduced in mice that are doubly mutant in endothelial and neuronal nitric oxide synthase. Cell 87: 1015-1023.

Stuehr, D.J. 1997. Structure-function aspects in the nitric oxide synthases. Annu. Rev. Pharmacol. Toxicol. 37: 339-359.

Stuehr, D.J., O.A. Fasehun, N.S. Kwon, S.S. Gross, J.A. Gonzalez, R. Levi, and C.F. Nathan. 1991. Inhibition of macrophage and endothelial cell nitric oxide synthase by diphenyleneiodonium and its analogs. FASEB J. 5: 98-103.

Tobin, J.R., L.K. Gorman, M.G. Baxter, and R.J. Traystman. 1995. Nitric oxide synthase inhibition does not impair visual or spatial discrimination learning. Brain Res. 69: 177-182.

von Bartheld, C.S. and A. Schober. 1997. Nitric oxide synthase in learning-relevant nuclei of the chick brain: morphology, distribution, and relation to transmitter phenotypes. J. Comp. Neuro. 383: 135-152.

Wang, Y.-X. and C.C.Y. Pang. 1993. Functional integrity of the central and sympathetic nervous systems is a prerequisite for pressor and tachycardic effects of diphenyleneiodonium, a novel inhibitor of nitric oxide synthase. J. Pharmacol. Exp. Ther. 265: 263-272.

Wang, Y.-X., C.I. Poon, K.S. Poon, and C.C.Y. Pang. 1993. Inhibitory actions of diphenyleneiodonium on endothelium-dependent vasodilatations in vitro and in vivo. Br. J. Pharmacol. 110: 1232-1238.

Wilson, R.I., A. Gödecke, R.E. Brown, J. Schrader, and H.L.
Haas. 1999. Mice deficient in endothelial nitric oxide synthase exhibit a selective deficit in hippocampal long-term potentiation. Neuroscience 90: 1157-1165.

Wilson, R.I., J. Yanovsky, A. Gödecke, D.R. Stevens, J. Schrader, and H.L. Haas. 1997. Endothelial nitric oxide synthase and LTP. Nature 386: 338-223.

Yea, C.M., A.R. Cross, and O.T.G. Jones. 1990. Purification and some properties of the $45 \mathrm{kDA}$ diphenylene iodonium-binding flavoprotein of neutrophil NADPH oxidase. Biochem. J. 265: 95-100.

Yun, H.Y., V.L. Dawson, and T.M. Dawson. 1996. Neurobiology of nitric oxide. Crit. Rev. Neurobiol. 10: $291-316$.

Zhang, H.Q., W. Fast, M.A. Marletta, P. Martasek, and R.B. Silverman. 1997. Potent and selective inhibition of neuronal nitric oxide synthase by $\mathrm{N}^{\omega}$-Propyl-L-arginine. J. Med. Chem. 40: $3869-3870$.

Received June 10, 1999; accepted in revised form August 13, 1999. 


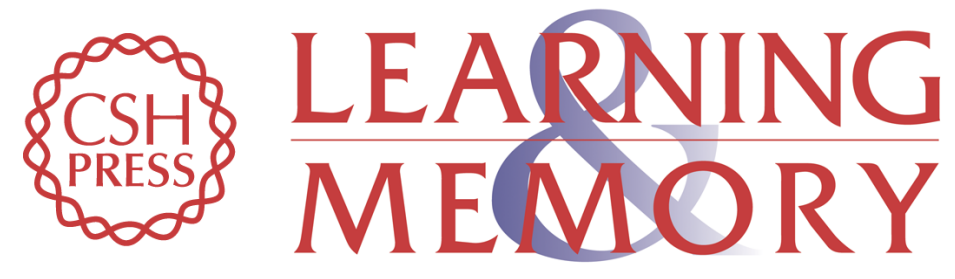

\section{Inhibition of the Endothelial Isoform of Nitric Oxide Synthase Impairs Long-Term Memory Formation in the Chick}

Nikki S. Rickard, Marie E. Gibbs and Kim T. Ng

Learn. Mem. 1999, 6:

Access the most recent version at doi:10.1101//m.6.5.458

References This article cites 50 articles, 12 of which can be accessed free at: http://learnmem.cshlp.org/content/6/5/458.full.html\#ref-list-1

License

Email Alerting Receive free email alerts when new articles cite this article - sign up in the box at the Service top right corner of the article or click here. 